\title{
Spatial Distribution of Fibroblast Growth Factor Receptor 2 in Normal and Lesioned Central Nervous System of Pleurodeles waltlii
}

\author{
${ }^{1,2,4}$ Marie Moftah, ${ }^{1,2}$ Marc Landry, \\ ${ }^{1,2}$ Frederic Nagy and ${ }^{1,3}$ Jean-Marie Cabelguen
}

\author{
${ }^{1}$ IINS, CNRS UMR 5297, Central Mechanisms of Pain Sensitization, Bordeaux, France \\ ${ }^{2}$ Université de Bordeaux, IINS, CNRS UMR 5297, Central Mechanisms of Pain Sensitization, Bordeaux, France \\ ${ }^{3}$ Université de Bordeaux, INSERM U862, Neurocentre Magendie, Pathophysiology of Spinal Networks, Bordeaux, France \\ ${ }^{4}$ Department of Zoology, Faculty of Science, Alexandria University, Alexandria, Egypt
}

Received 2012-08-20, Revised 2012-08-28; Accepted 2012-09-04

\begin{abstract}
Fibroblast Growth Factors (FGFs) have been implicated in numerous cellular processes including proliferation, migration, differentiation and neuronal survival. One of these growth factors, Fibroblast Growth Factor 2 (FGF2), is apparently implicated in the ability of the adult salamander (Pleurodeles waltlii) to recover locomotion following complete transection of the spinal cord. In a previous study, we reported up regulation of FGF2 during regeneration of damaged axons and recovery of hind limb locomotion. In this study reported here, we investigated the spatial distribution of FGFR2 -one of the receptors that mediate the effects of FGF2-using a variety of techniques, namely, western blot, immunohistochemistry and in situ hybridization. We find that in intact animals FGFR2 is mainly expressed in the most posterior part of body Spinal Cord (SC3) specifically in neurons. However, lesioning the spinal cord produces increased expression in Brainstem (BS) neurons and decreased expression in posterior parts of the spinal cord not only in neurons but also in the neuroglial ependymal cells lining the central canal. This suggests that FGF2 simultaneously activates FGFR1 and 2 , perhaps at different points in the regeneration process and thus FGFR2 might play at least an indirect role in the spontaneous regeneration observed in this species and might be relevant to the treatment of spinal cord lesions in humans. Verification of this possibility will require studies of additional time points.
\end{abstract}

Keywords: Spinal Lesion, In Situ Hybridization, Brainstem, Spinal Cord, Regeneration

\section{INTRODUCTION}

Unlike mammals and most other vertebrates, the adult salamander (Pleurodeles waltlii) has the ability to spontaneously recover locomotion following complete transection of the spinal cord (Piatt, 1955; Davis et al., 1990; Chevallier et al., 2004). Recovery of function, which takes approximately 3 months, is accompanied by the functional regeneration of lesioned brainstem and spinal fibers crossing the transection (Davis et al., 1990; Chevallier et al., 2004). Although the underlying molecular mechanisms remain unclear, it is known that Fibroblast Growth Factor 2 (FGF2) and its receptors can contribute to the proliferation of neural progenitor cells (Zhang et al., 2000). It seems likely therefore that FGF2 plays a role in the regeneration process. Studies have observed up regulation of FGF2 mRNA and protein of complete cord transection, not only in salamanders (Moftah et al., 2008) but also in young rat (Qi et al., 2003). In both cases, observations have been linked to the ability of descending axons to regenerate in the transected spinal cord, leading to at least partial recovery of locomotion (Inoue et al., 1998; Wakabayashi et al., 2001). This suggests a possible therapeutic role for FGF2 and FGF2 receptors in human cases of spinal lesion (McDonald and Sadowsky, 2002).

Corresponding Author: Marie Moftah, IINS, CNRS UMR 5297, Central Mechanisms of Pain Sensitization, Bordeaux, France 
A number of studies have investigated regeneration of the salamander spinal cord following transection of the spine at the cervical, thoracic and lumbar levels (Piatt, 1955; Davis et al., 1990) for review). In each case, the regenerated tail contains a complete spinal cord with sensory ganglia, motor neurons and interneurons, spinal projection neurons and spinal tracts (Nordlander and Singer, 1978; Zhang et al., 2003).

FGF signaling is mediated by four types of receptors (FGFR1, FGFR2, FGFR3 and FGFR4), which all belong to the high affinity tyrosine kinase receptor family (Dionne et al., 1990; Keegan et al., 1991; Trueb, 2011). They are known to trigger the phosphorylation of signaling cascades and regulate protein synthesis and neuronal excitability. Studies in mice showed that the proper formation of the medial prefrontal cortex depends on the function of FGFR2 genes since they are required for up regulating the self renewal of radial glial precursor cells (Stevens et al., 2010). The function of FGF signaling in maintaining the self renewal and undifferentiated state of cortical stem cells is reminiscent of its role in the spinal cord stem zone (Kang et al., 2009). In comparison, following peripheral nerve injury in rats, studies suggest that FGFR2 expression in the Dorsal Root Ganglion (DRG) is reduced (Yamanaka et al., 2007). However, relatively little is known about FGFR 2 distribution in the CNS. Previous studies provide conflicting evidence (Pettmann et al., 1986; Finklestein et al., 1988; Grothe et al., 1991; Yamamoto et al., 1991; Gomez-Pinilla et al., 1992; Matsuda et al., 1992; Matsuyama et al., 1992; Woodward et al., 1992; Eckenstein et al., 1994) or are limited to specific areas of the brain (Cuevas et al., 1991; Frautschy et al., 1991; Matsuda et al., 1992; 1993; Stock et al., 1992; Tooyama et al., 1992; Tooyama et al., 1993a; 1993b; Gonzalez et al., 1994; Saarimaki-Vire et al., 2007).

In this study therefore, we used in situ hybridization to examine the distribution of mRNA for FGFR2 in the entire spinal cord and brainstem of healthy and transected Pleurodeles in order to get deeper insight as to the role of FGFR2 in spontaneous spinal cord regeneration in this species.

\section{MATERIALS AND METHODS}

\subsection{Animals}

Experiments were carried out as previously described (Moftah et al., 2008). In brief, 25 Urodele amphibians (Pleurodeles waltlii) were obtained from Blades Biological ltd (Kent, UK) and kept in aquaria at $19^{\circ} \mathrm{C}$. Surgical procedures, handling and housing of the animals were in accordance with protocols approved by the INSERM Ethics Committee and conformed to NIH guidelines.

\subsection{Spinalization}

Surgery was performed in aseptic conditions under general anesthesia as previously described (Moftah et al., 2008). In short, anesthetized animals were operated by completely cutting the spinal cord between segments 12 and 13. The wound was sutured and wound healing was complete 8 to 10 days post operative. Sham-operated animals were exposed to laminectomy but not spinal cord transection.

\subsection{In Situ Hybridization}

All animal groups were anaesthetized and treated for in situ hybridization as previously described (Moftah et al., 2008). In summary, brainstem and spinal cord were exposed by craniectomy and laminectomy, respectively spinal cord was then divided into three segments (SC1, SC2 and SC3) corresponding respectively to the anterior, middle and posterior regions of trunk spinal cord. SC1 and SC2 were pooled to represent the pre-lesional part of the cord (in spinalized animals). Brainstem (BS) and spinal cord were immediately but separately frozen by immersion in $-50^{\circ} \mathrm{C}$ isopentane (Merck) without fixation. All samples were stored in embedding medium (Tissue Tek, Sakura) to be sectioned and processed later on.

\subsection{Oligonucleotide Probes}

For in situ detection of FGFR2 mRNA, we used the following two fifty-mer oligonucleotide probes (Eurogentech, Seraing, Belgium) based on previously published gene sequences (Moftah et al., 2002):

\section{5'GGAAATGGACCAGGAACTTACTCTAAAAAGAT GGTCAGCTGGGATTCGGG3' 5'CCTGGTGTCAGGGTAGCTAGGTGAATACTGCT CCAGAGGTCCGCTGAGGT3'}

The probes were chosen from regions presenting few homologies with related mRNA sequences and were checked against the GenBank database.

As previously described (Landry et al., 2000), oligonucleotides were labeled in cobalt containing buffer with ${ }^{35} \mathrm{~S}$-dATP (Amersham) to a specific activity of 1 $4 \times 10^{9} \mathrm{cpm} / \mu \mathrm{g}$ and purified by ethanol precipitation.

\subsection{In Situ Hybridization}

Spinal cord and brainstem sections (265 section/region/animal/experiment) were $14 \mu \mathrm{m}$ thick and processed as described earlier (Landry et al., 2000). Briefly, sections were incubated at $42^{\circ} \mathrm{C}$ with $0.5 \mathrm{ng}$ of each of the radioactively labeled probes. After hybridization, they were rinsed for four times at $55^{\circ} \mathrm{C}$ followed by $30 \mathrm{~min}$ at room temperature. Radioactivity 
was revealed by dipping sections into Ilford K5 nuclear emulsion (Ilford, Mobberly, Cheshire, UK), diluted 1:1 with distilled water, developing them in Kodak D19 and fixing them in Kodak 3000. Sections were then counterstained with $0.25 \%$ cresyl violet acetate $(\mathrm{pH} 4)$ (Sigma) and mounted in glycerol.

\subsection{Western Blots}

The presence of FGFR2 protein was determined by Western Blot. Previously removed and frozen brainstem and SC3 $(n=5)$ were separately homogenized in ice cold buffer (10 mM HEPES, $350 \mathrm{mM}$ sucrose and $5 \mathrm{mM}$ EDTA, pH 7.4) containing protease inhibitors (pepstatin A $1 \mu \mathrm{g} \mathrm{mL} L^{-1}$, leupeptin $1 \mu \mathrm{g} \mathrm{mL}^{-1}$, aprotinin $1 \mu \mathrm{g} \mathrm{mL}^{-1}$, PMSF $1 \mu \mathrm{g} \mathrm{mL} \mathrm{m}^{-1}$, benzamidine $0.1 \mu \mathrm{g} \mathrm{mL}^{-1}$ and calpain inhibitors I and II $8 \mu \mathrm{g} \mathrm{mL}^{-1}$ ) (Sigma). Homogenates were centrifuged at $1500 \mathrm{rpm}$ for $8 \mathrm{~min}$. 1\% Triton X-100 (Sigma) was added and the supernatants were centrifuged at $14000 \mathrm{rpm}$ for $1 \mathrm{~h}$ at $4^{\circ} \mathrm{C}$. Protein content was determined using Bradford assay (Bio-Rad, Hercules, CA). Western Blots were performed with $40 \mu \mathrm{g}$ of proteins and repeated five times. Samples were resuspended in Laemmli (1970), fractionated by SDSPAGE using a $10 \%$ acrylamide gel and then transferred to PVDF membrane (Bio-Rad). The membrane was washed in blocking buffer and incubated overnight at $4^{\circ} \mathrm{C}$ with mouse anti-FGFR2 IgM (Chemicon, Temecula, CA) antibody (1:200 in blocking buffer: BIORAD, Marnes-laCoquette, France). Immunoreactivity was detected using goat peroxidase-conjugated anti-mouse IgM (Bethyl, Texas, USA) and visualized using ECL detection system (Cell Signaling, Beverly, MA).

\subsection{Immunohistochemistry}

Anaesthetized animals ( $\mathrm{n}=5$ /experiment) were perfusion-fixed via the ascending aorta. Brainstem and spinal cord were dissected out, post-fixed in the same fixative and rinsed for at least $24 \mathrm{~h}$ in $0.1 \mathrm{M} \mathrm{PB}(\mathrm{pH} 7.4)$ containing $15 \%$ sucrose and $0.02 \%$ sodium azide (Sigma) for cryoprotection. Sections were triple labeled with mouse anti-FGFR2 IgM, mouse anti-NeuN (Abcam, Paris, France) and rabbit anti-GFAP (Dako SA, Trappes, France). This procedure made it possible to avoid cross reactivity between same species-raised antibodies (as previously described in Moftah et al. (2008).

In short, blocked sections were incubated with mouse anti-FGFR2 IgM primary antibody $(1: 1000$ in TNT/BSA). After rinsing in TNT, they were incubated with anti-mouse horseradish peroxidase (HRP)conjugated secondary antibody (Dako). Peroxidase activity was then developed with fluorescein-conjugated tyramide (Perkin Elmer, Boston, MA) according to the manufacturer's instructions, as previously described
(Landry et al., 2004). Rinsed sections were incubated with mouse anti-NeuN (1:100 in TNT/BSA) and rabbit anti-GFAP (1:500 in TNT/BSA) and rinsed in TNT. GFAP was detected by incubating sections with Alexa 647-conjugated donkey anti-rabbit secondary antibody (Invitrogen, Cergy Pontoise, France) (1:500 in TNB). Immunohistochemical detection of NeuN was visualized with biotinylated anti-mouse antibody (Vector, Burlingame, CA) (1:100 in TNB) and Alexa 568conjugated streptavidin (Invitrogen) (1:500 in TNB). Sections were then rinsed and mounted.

\subsection{Imaging}

Slides were examined; bright field light microscopy micrographs and triple immunostainings were taken using a Zeiss Axiophot 2 microscope (Zeiss, Jena, Germany). Digital images were optimized for image resolution (300 dpi final resolution), brightness and contrast using Adobe Photoshop CS3 (Adobe System, San Jose, CA, USA).

\subsection{Data Analyses}

The number of labeled cells and the labeling intensity were quantified as previously described (Landry et al., 2000). Cellular profiles containing three times more grains than mean background grain densities were considered labeled. Cell profiles were manually outlined as previously described (Moftah et al., 2008). Delineation was based exclusively on staining and not on shape, size or other measurable quantities. The number of silver grains per cresyl violet counterstained cell was counted semi automatically using MetaMorph Offline 6.1 software (Universal Imaging Corporation). Data were expressed as grain density per $\mu \mathrm{m}^{2} \pm \mathrm{SEM}$ in calibrated photomicrographs. Transmitted light photomicrographs were taken for at least 500 fields (700 $\mu \mathrm{m}^{2}$ each), in each experiment.

Data were imported into a spreadsheet program (Sigma Plot software, Jandel Scientific) that calculated and graphed the density of FGFR2 mRNA expression and the number of labeled cells. Data were compared using one way ANOVA tests and processed using standard statistical analysis techniques (Sigma Stat software). Differences were considered to be significant when $\mathrm{p} \leq 0.05$.

\section{RESULTS}

\subsection{FGFR2 in Brainstem and Body Spinal Cord in Intact Animals}

In intact animals, western blot assays showed significantly less FGFR2 protein in brainstem than in the 
posterior portion of trunk spinal cord (SC3) (Fig. 1 A and B) $(\mathrm{p}=0.01)$. This was even more evident in the case of the pooled anterior spinal cord regions $(\mathrm{SC} 1,2)$ where FGFR2 protein decreased $(\mathrm{p}=0.014)$. To verify if these differences relate to changes in transcriptional activity, we studied the distribution of FGFR2 mRNA by using in situ hybridization (Fig. 2 and 3 A, B and E, F). Analysis of grain density confirmed the western blot data. More specifically, the highest levels of FGFR2 mRNA were found in SC3 as seen in Fig. 2A. Grain density had, however, a complex rostrocaudal profile since it first decreased passing from BS to $\mathrm{SC} 1,2(p=0.005)$ then increased reaching around 50\% more in SC3 $(p=$ 0.001 ). Meanwhile, the number of labeled cells shown in Fig. 2B indicates that around 20\% of the total cell number was labeled in the entire neural axis. These findings suggest the presence of a rostrocaudal gradient in the number of cells expressing the receptor in intact animals.

Histologically, FGFR2 mRNA was mainly found along the midline (Fig. 3, A and B) in the intact brainstem. However, in spinal cord sections, receptors were obvious in the ventrolateral region as shown in Fig. 3E and F.

\subsection{FGFR2 in Brainstem in Spinal-Transected Animals}

Based on results from previous studies (Chevallier $e t$ al., 2004; Moftah et al., 2008) we measured FGFR2 mRNA density at 1-2 weeks after transection, when the animals were unable to display hind limb locomotor movements.

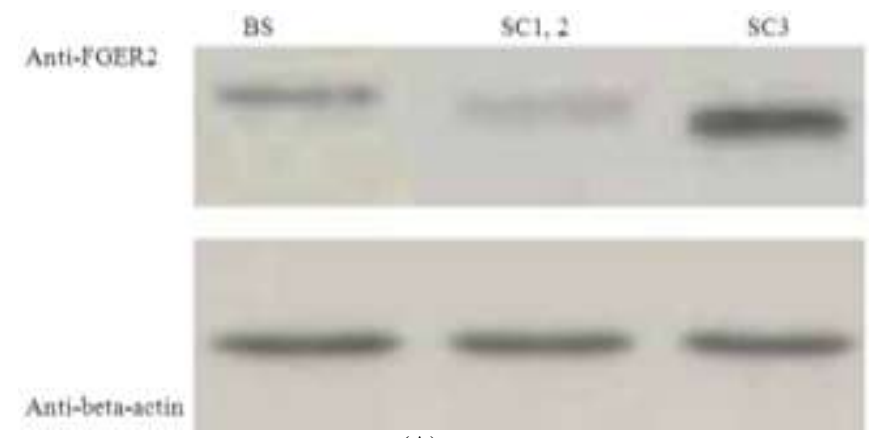

(A)

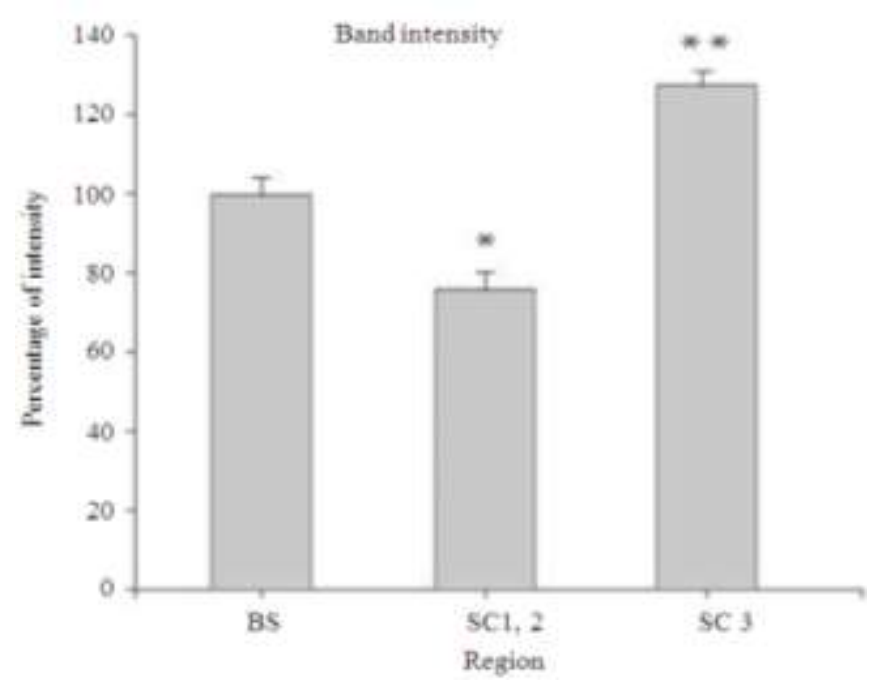

(B)

Fig. 1. Immunoblot analysis of FGFR2 expression: (A) shows that a band detected by an anti-FGFR2 antibody is reduced in normal $(\mathrm{n}=5$ ) pooled anterior parts of spinal cord: SC1, 2 (upper middle band) compared to normal $(\mathrm{n}=5$ ) brainstem: BS (upper left band) and the most posterior part of normal $(\mathrm{n}=5$ ) spinal cord: SC3 (upper right band). Lower panel shows beta-actin in BS, SC1, 2 and SC3 in intact animals. (B) BS, SC1, 2 and SC3 band intensity compared to beta-actin bands. Note the maximum intensity in SC3. The symbols above each bar indicate the statistical significance with the BS bar. (***: $\mathrm{p} \leq 0.001 ; * *: \mathrm{p} \leq 0.01 ; *: \mathrm{p}<0.05)$ 

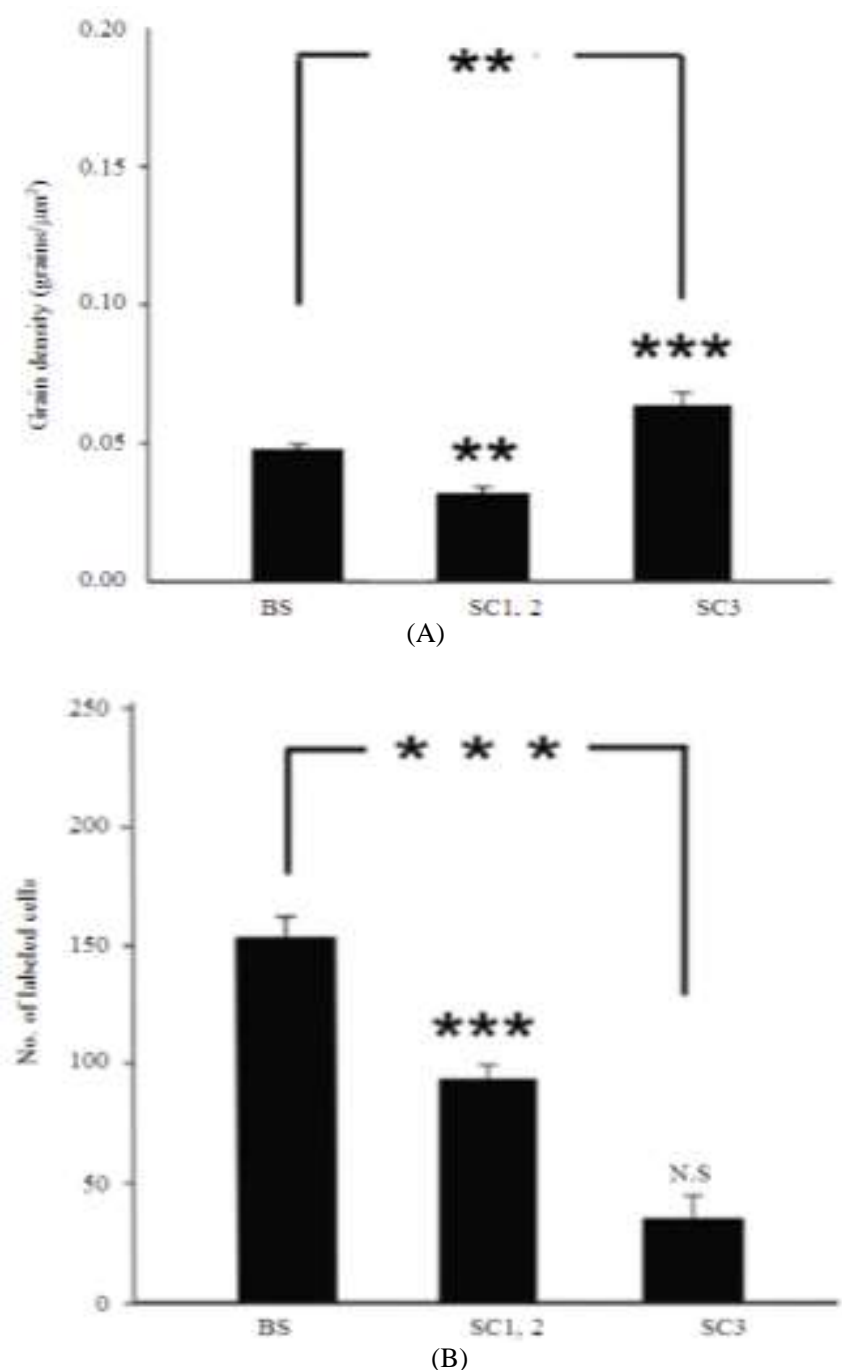

Fig. 2. FGFR 2 mRNA expression along the brainstem and spinal cord in intact animals: A shows grain density and B shows the number of labeled cells for FGFR2 mRNAs. FGFR2 mRNA grain density decreases in SC1, 2 but again increases going posteriorely in SC3 while the number of labeled cells gradually decreases. The symbols above each bar indicate the statistical significance with the previous bar. $(* * *: \mathrm{p} \leq 0.001 ; * *: \mathrm{p} \leq 0.01 ; *: \mathrm{p}<0.05)$

A second set of measurements was taken 15 weeks post op., when the animals had fully recovered locomotion and reinnervation of the spinal cord below the lesion was complete (Piatt, 1955; Davis et al., 1990; Chevallier et al., 2004). As controls, we examined the distribution of FGFR2 mRNA in sham-operated animals.

Tissue sections of BS (Fig. 3C and D) and SC3 (Fig. 3G and $\mathbf{H}$ ) were examined 15 weeks post operatively to assess the distribution of FGFR2 mRNA. Positive and negative cell profiles were found, the former being more heavily labeled than in intact animals (Fig. 3B), mainly in brain stem (Fig. 3D). Spinal cord, however, shows no clear increase in the amount of FGFR2 mRNA grains, which are prominent in a ventrolateral position (Fig. 3H).

Analysis of BS from sham-operated animals 15 days post op. showed no significant difference in grain density with respect to intact animals $(\mathrm{p}=0.3)$ (Fig. $\mathbf{4 A}$, white bars), though the number of labeled cells was slightly higher (Fig. 4B, white bars). There were no significant differences in grain density between spinalized, shamoperated and intact animals. This suggests that the slight increase in the number of FGFR2 positive $\left(\mathrm{FGFR} 2^{+}\right.$) cells was due to the surgical operation per se rather than to spinal cord lesion. 

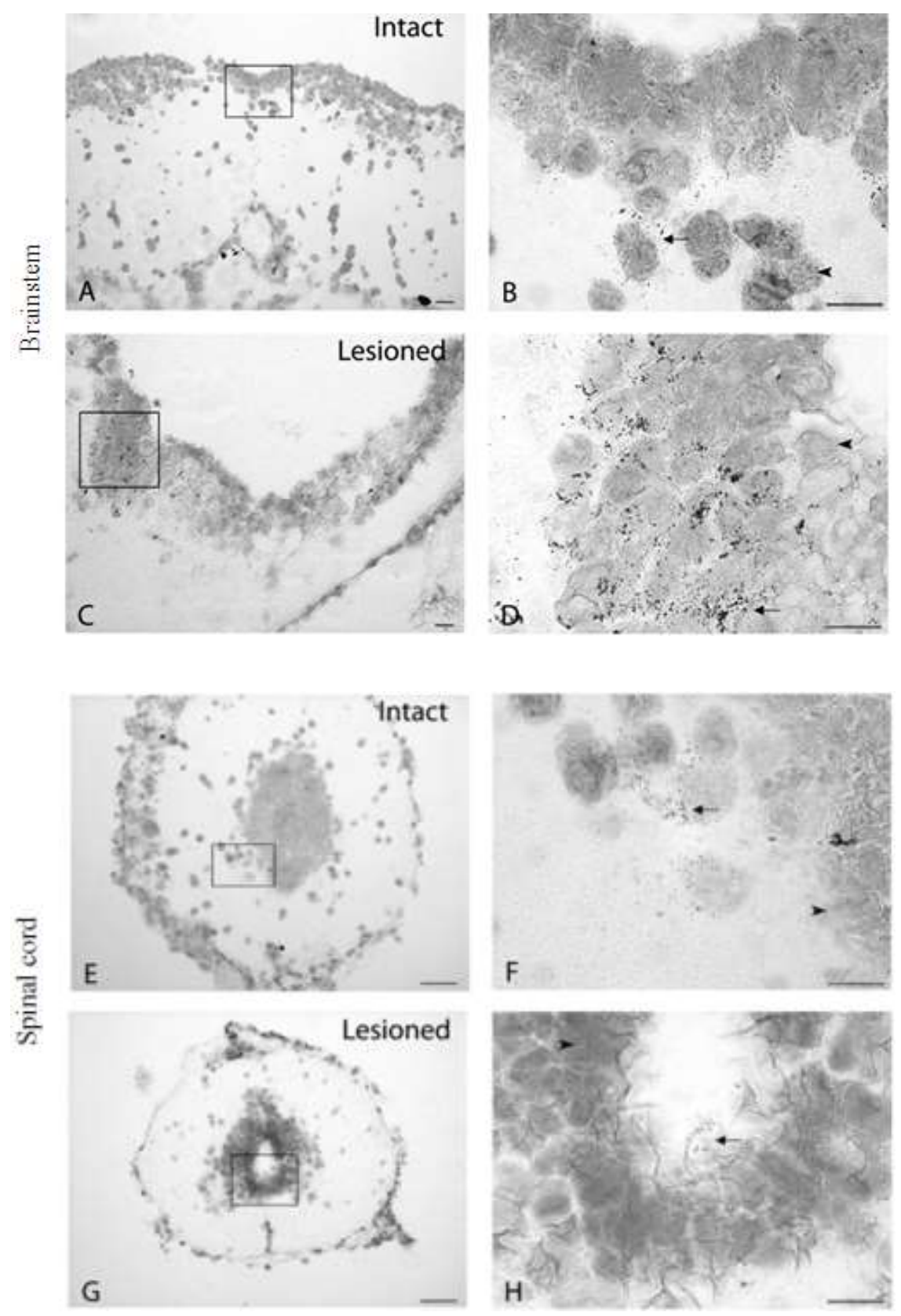

Fig. 3. Localization of FGFR2 mRNA in cross sections of brainstem and spinal cord in intact and spinal-transected animals: A-D show in situ hybridization in intact (A and $\mathrm{B})$ and lesioned $(\mathrm{C}$ and $\mathrm{D})$ animals' brainstem. E-H show posterior spinal cord in intact $(\mathrm{E}$ and $\mathrm{F})$ and lesioned $(\mathrm{G}$ and $\mathrm{H})$ animals. Squares in $\mathrm{A}, \mathrm{C}, \mathrm{E}$ and $\mathrm{G}$ are enlarged in $\mathrm{B}, \mathrm{D}, \mathrm{F}$ and $\mathrm{H}$ respectively. All sections are dorsoventrally oriented. Arrows in B, D, F and H show the grains demarking hybridized FGFR2 mRNAs, while arrowheads point at non labeled cells. Grains demarking hybridized FGF2 mRNAs are more pronounced in number in the midline of the brainstem in intact animals (A) while they are more abundant laterally flanking the midline in lesioned animals (C). Note the significant increase in grain density between BS sections in different conditions (B and D). In spinal cord sections, intact and lesioned animals $(\mathrm{E}-\mathrm{H})$ show a ventrolateral distribution of FGFR2 grains (arrow in $\mathrm{H}$ ). Scale bars $=40 \mu \mathrm{mh}$ bar indicate the statistical significance with intact animals' level. (***: $\mathrm{p} \leq 0.001 ; * *: \mathrm{p} \leq 0.01 ; *: \mathrm{p}<0.05)$ 


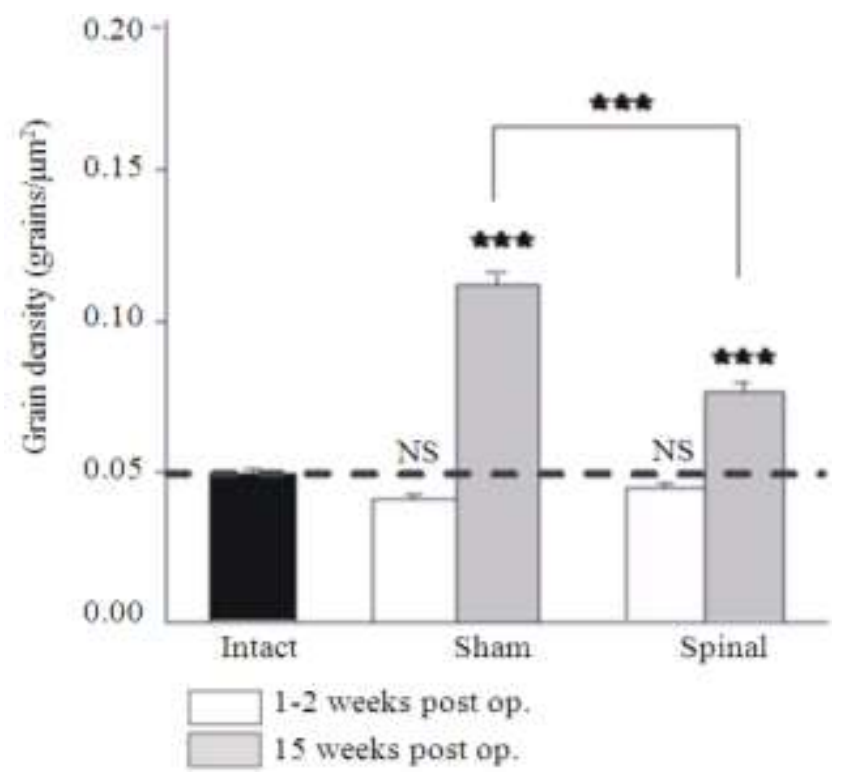

(A)

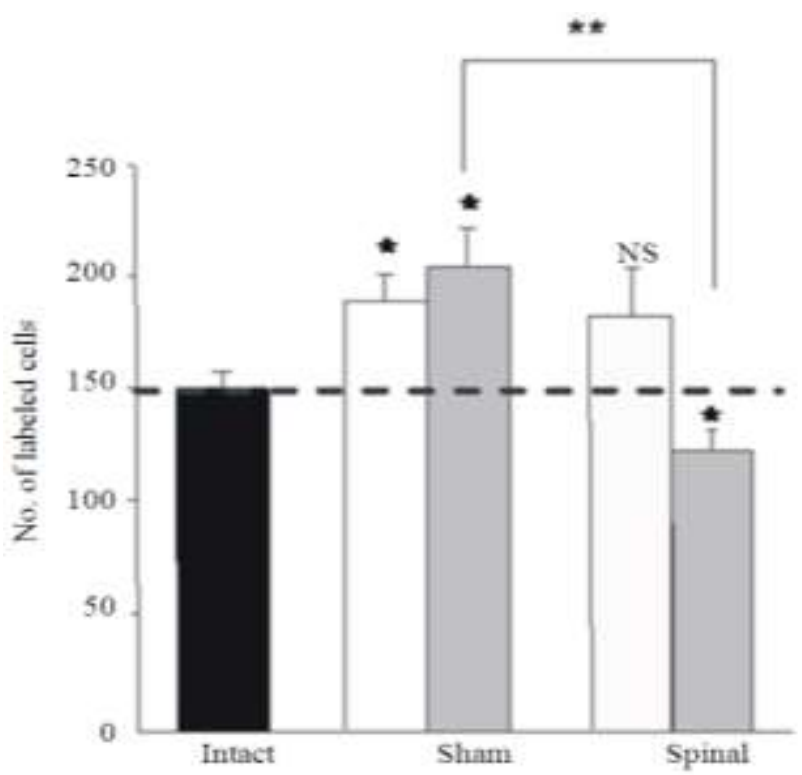

(B)

Fig. 4. FGFR2 mRNA expression in the brainstem of spinal-transected animals: A: FGFR2 mRNA grain density. The black bar represents FGFR2 mRNA grain density measured in intact animals. In sham-operated animals, the level of grain density was close to control 1-2 weeks post-op (sham, white bar), while a highly significant increase appeared 15 weeks post-op (sham, grey bar). Spinal-transected animals had almost the same grain density levels as intact and sham-operated animals, 1-2 weeks post-op (spinal, white bar) and a significant increase 15 weeks post-op (spinal, grey bar) although significantly less than shamoperated animals. B: Number of FGFR $2^{+}$cells. The black bar represents the number of FGFR2 ${ }^{+}$cells measured in intact animals. A slight increase was observed in sham-operated animals (sham, white and grey bars). In spinal-transected animals the FGFR2 ${ }^{+}$cells number was unaltered 1-2 weeks post-op. (spinal, white bar) compared to both intact and sham-operated animals, while it decreased 15 weeks post-op. (spinal, grey bar). This decrease is significant compared to sham-operated animals. Symbols above each bar indicate the statistical significance with intact animals' level. (***: $\mathrm{p} \leq 0.001 ; * *: \mathrm{p} \leq 0.01 ; *: \mathrm{p}<0.05)$ 
15 weeks after surgery, sham-operated animals still had higher grain densities for FGFR2 than intact animals (Fig. 4A, left grey bar). Spinalized animals also had higher densities; though lower than those in sham operated animals $(\mathrm{p}<0.001)$ (Fig. 4A, right grey bar). There was a slim increase in labeled cells numbers in sham-operated and intact animals $(p=0.9)$. However spinalized animals (Fig. 4B, right grey bar) had slightly lower numbers of labeled cells than intact $(P=0.01)$ or sham operated animals $(p=0.008)$. Together these results suggest that observed increases in FGFR2 expression were at least partially an effect of laminectomy. Vice versa, the decrease in the number of FGFR2 $^{+}$cells in spinalized animals was probably a result of cord injury, perhaps reflecting the death of descending brainstem neurons projecting below the transection.

\subsection{FGFR2 in Spinal Cord in Spinal-Transected Animals}

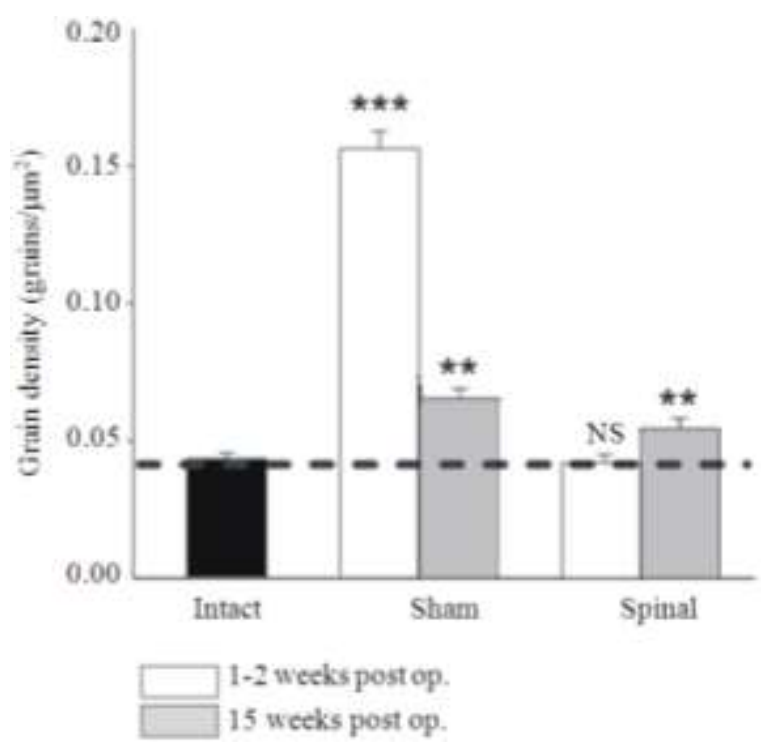

(A)
Pooling SC1 and SC2, we investigated only one prelesional portion of spinal cord. We found that in shamoperated animals FGFR2 grain density and numbers of labeled cells dramatically increased 1-2 weeks after surgery (Fig. 5, sham white bars). In spinalized animals grain density did not differ significantly from the levels observed in intact animals while the number of cells slightly fell (Fig. 5, spinal white bars). 15 weeks after surgery grain densities in sham-operated and spinalized animals (Fig. 5A, grey bars) were almost similar $\left(0.0625 \pm 0.0034\right.$ grains $/ \mu \mathrm{m}^{2}$ and $0.0533 \pm 0.0051$ grains $/ \mu \mathrm{m}^{2}$ respectively). In both sets of animals, densities were significantly higher than in intact animals $(p<0.006)$ but much lower than those recorded in shamoperated animals, 1-2 weeks after surgery. Moreover, cell numbers were not altered in both sham-operated and lesioned animals ( $p=0.084$ and 0.07 respectively) after 15 weeks of the operation (Fig. 5B, grey bars). This suggests that the observed effects were due to the surgical operation and not to spinal cord lesion.

Fig. 5. FGFR 2 mRNA expression in pre-lesional spinal cord stump $(\mathrm{SC} 1,2)$ in spinal-transected animals: A: FGFR2 mRNA grain density. Same representation and same conventions as in Fig. 4A; In sham-operated animals, the level of grain density dramatically increased 1-2 weeks post-op (sham, white bar), while at 15 weeks post-op, an increase is still obvious but almost half of that of the previous time point (sham, grey bar). Spinal-transected animals had almost the same grain density levels, 12 weeks post-op, as control (spinal, white bar) and a significant increase 15 weeks post-op reaching that of the shams (spinal, grey bar). B: Number of FGFR2 ${ }^{+}$cells. Same representation and same conventions as in Fig. 4B; A slight increase was observed in sham-operated animals 1-2 weeks post-op (sham, white bar) while the number of labeled cells did not change 15 weeks post-op (sham, grey bars). In spinal-transected animals, the FGFR2 ${ }^{+}$cells number slightly decreased $1-2$ weeks postop. (spinal, white bar), while it was unaltered 15 weeks post-op. (spinal, grey bar). Symbols above each bar indicate the statistical significance with intact animals' level. $(* * *: \mathrm{p} \leq 0.001 ; * *: \mathrm{p} \leq 0.01 ; *: \mathrm{p}<0.05)$ 
Marie Moftah et al. / American Journal of Neuroscience 3 (2) (2012) 41-53

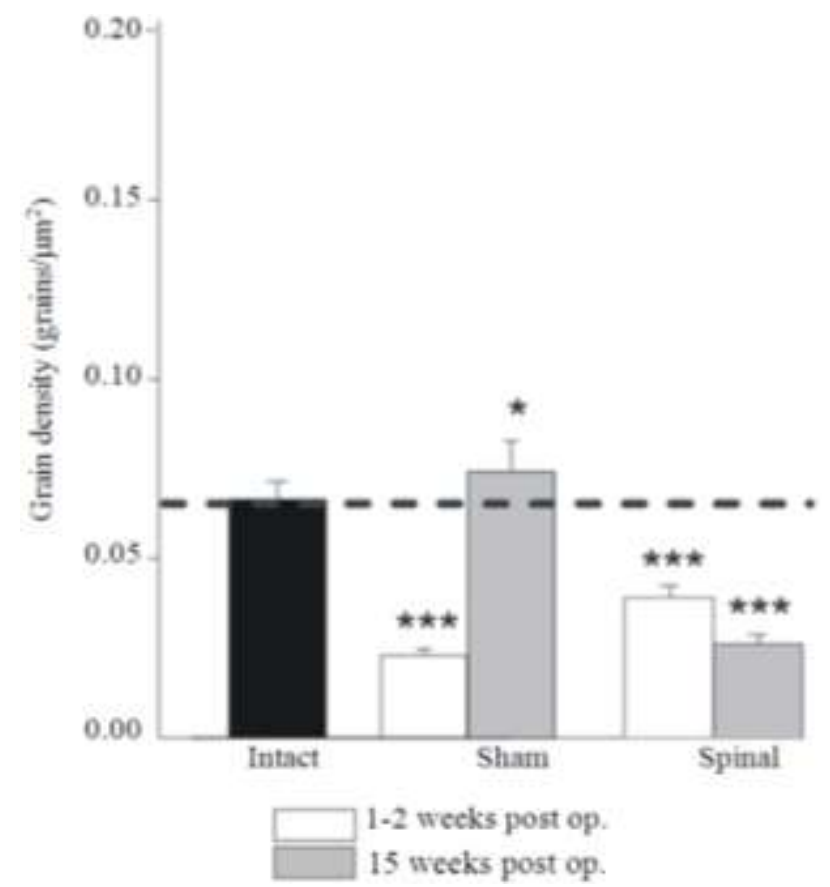

(A)

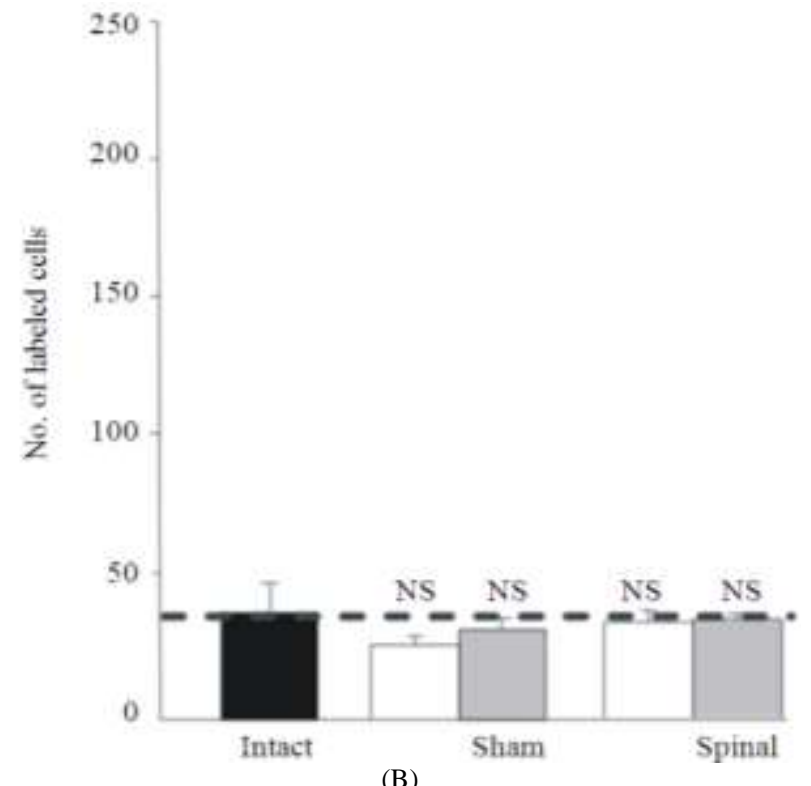

Fig. 6. FGFR 2 mRNA expression in spinal cord stump (SC3) in spinal-transected animals. A: FGFR2 mRNA grain density. Same representation and same conventions as in Fig. 4A; In sham-operated animals, the level of grain density dramatically decreased 1-2 weeks post-op (sham, white bar), while at 15 weeks post-op, a slight increase was observed (sham, grey bar). Spinal-transected animals showed a severe drop in their grain density levels 1-2 weeks post-op (spinal, white bar), further decreased 15 weeks post-op reaching almost half of the control level (spinal, grey bar). B: Number of FGFR2 ${ }^{+}$cells. Same representation and same conventions as in Fig. 4B; No change in the number of labeled cells was observed in any of the conditions (sham, white bar and grey bars and spinal, white and grey bars). Symbols above each bar indicate the statistical significance with intact animals' level. (***: $\mathrm{p} \leq 0.001 ; * *: \mathrm{p} \leq 0.01 ; *: \mathrm{p}<0.05)$ 


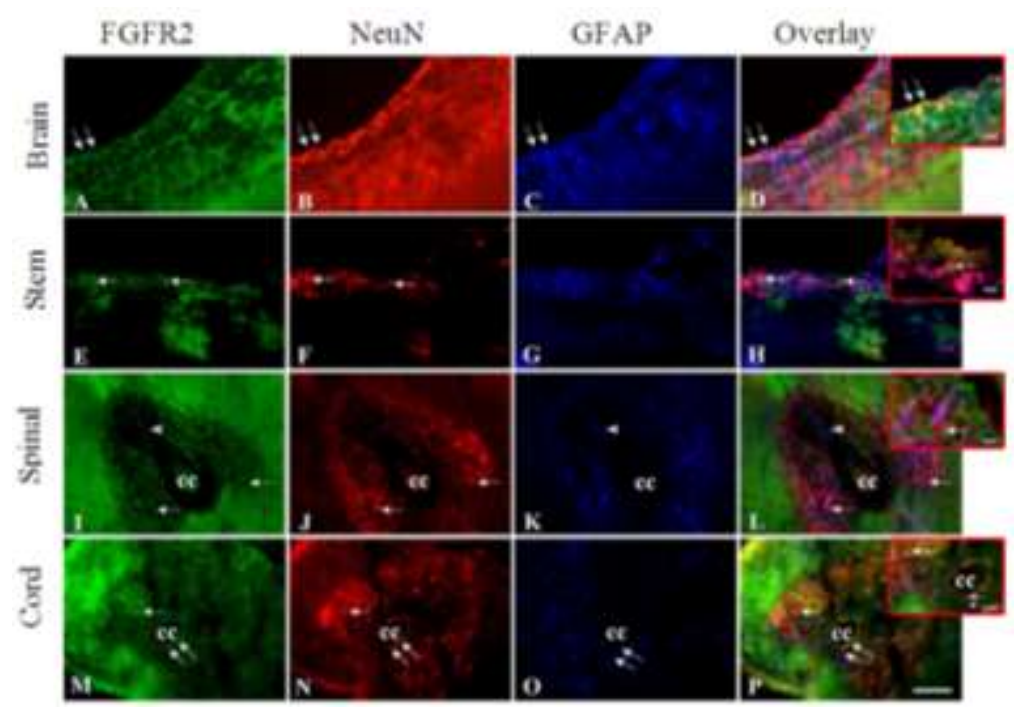

Fig. 7. Immunohistochemical analysis of FGFR2 distribution in the brainstem and the distal (sub-lesional) spinal stump (SC3) of spinal-transected animals. FGFR2 immunoreactive (IR) cells are shown in green (A, E, I and M), NeuN IR cells in red (B, F, J and N), GFAP IR cells in blue (C, G, K and O). D, H, L and P are overlays with red-squared enlarged inserts. Brainstem: A - D: sham operated animals, E - H: Spinal-transected animals, 15 weeks post-op. In sham-operated animals (A), FGFR2 was expressed in neuroglial cells (double arrows in A-D). FGFR2 expression increased after 15 weeks of spinal cord transection mainly in neurons (arrows in E, F and H) Distal spinal stump: I-L: sham operated animals, M-P: Spinal-transected animals, 15 weeks post-op. In sham-operated animals, FGFR2 was mainly seen in neurons (arrows in I, J and L) in a ventrolateral position compared to the central canal (cc) but not in glial cells (arrowheads in K and L). It was prominent, at 15 weeks postop., in ependymal cells (double arrows in M-P) and in neurons (arrows in M, N and P). Ependymal cells, which were neuroglial cells, expressed both NeuN and GFAP (double arrows in N and O). Scale bar: $80 \mu \mathrm{m}$, insert scale bar: $20 \mu \mathrm{m}$

In SC3, sham-operated and spinalized animals both showed a large decrease in FGFR2 grain density, 1-2 weeks after surgery (Fig. 6A, white bars). In shamoperated animals grain density increased slightly 15 weeks after surgery (Fig. 6A, grey bars) while in spinalized animals, it continued to decrease $(p<0.001)$. Numbers of labeled cells were similar to those observed in intact animals in both sets of animals at all time points ( $p=0.257$ in shams and 0.28 in spinals) (Fig. 6). Altogether, these findings suggest that at least part of the observed drop in grain densities was due to the spinal lesion and that FGFR2 ${ }^{+}$expression in spinalized animals is down regulated throughout the recovery process. Taken together, these findings suggest that the spinal lesion caused a decrease in $F G F R$ gene activation.

To examine whether the observed reduction in the expression of mRNA from FGFR2 after spinal cord injury led to reduced protein synthesis, we used immunohistochemistry to detect FGFR2 protein in neuronal and glial cells in BS (Fig. 7 A-D) and in spinal cord (Fig. 7I-L). The assay showed that, in intact animals, FGFR2 protein was present in both types of cell in BS
(Fig. 7D), but that in spinal cord it was essentially limited to neurons (Fig. 7L). The positioning of FGFR2 protein was similar to that of the FGFR2 mRNA observed in the in situ hybridization study. 15 weeks after spinal lesion, the main FGFR2 ${ }^{+}$cells in BS were neurons (Fig. 7E-H). In the spinal cord, however, neuroglial ependymal cells lining the central canal were the main containers of FGFR2 protein (Fig. 7M-P).

\section{DISCUSSION}

Compared to our previous study (Moftah et al., 2008), we show here that, in intact Pleurodeles, the pattern of distribution of FGFR2 mRNA is opposite to that of its ligand (FGF2). Increased expression of FGFR2 in the posterior part of the spinal cord may be correlated with decreased levels of FGF2. However, histologically, they are seen in the same ventrolateral position in spinal cord cross sections. Judged by their morphology, size and position, the main cells expressing FGFR2 appear to be motor neurons.

In the present study, we analyzed the spatial distribution of FGFR2 mRNA in brainstem and spinal 
cord from adult Pleurodeles. Our findings show that in normal animals, expression of FGFR2 mRNA is significantly higher in the most posterior part of the spinal cord than in the BS. The rostrocaudal gradient in the number of cells expressing the receptor suggests the existence of an increasing gradient of grain density in individual cells.

We go on to show that spinal injury at the mid trunk level modifies this distribution. In lesioned animals, the highest levels of expression are observed in BS with no significant drop in SC1 and 2. By contrast, expression of FGFR2 in posterior segments of the cord is reduced. This finding is evidence in favor of the suggestion by Chevallier et al. (2004) that the recovery of locomotor activity is underlined by descending BS axons regeneration. It is probable that the observed post lesion increase in rostral FGFR2 facilitates the high regenerative capacity of reticulospinal neurons already seen in previous studies (Davis et al., 1990; Chevallier et al., 2004). Increased rostral expression of FGFR2 matched the increased expression of FGF2 reported in our previous work (Moftah et al., 2008). This is evidence that FGF2 contributes to spinal cord regeneration, in Pleurodeles and that this effect is mediated by FGFR2.

If we consider spinal cord results together with findings from BS we observe an overall decrease in FGFR2 expression in spinalized as opposed to shamoperated animals. This appears to be matched by a fall in the overall number of FGFR2 expressing cells. The observed drop in the number of labeled cells in BS and SC1 \& 2 suggests that in some individual cells FGFR2 expression may in fact be up regulated.

Given that lesioned animals show a decrease in FGFR2 expression in SC3, it is probable that the direct onsite regenerative effect of FGF2 depends on other receptors. It is nonetheless possible that FGFR2 contributes to the proliferation of the surrounding tissue, including neuroglial cells in the ependymal tube. This possibility is supported by the observed increase in the receptor's mRNA in sham-operated animals, where no spinal cord lesion was performed and only the surrounding tissue healed and is consistent with the findings of our previous FGF2 study in sham-operated salamanders (Moftah et al., 2008).

Our immunohistochemical data shows that in spinalized animals, FGFR2 protein is mainly located in neuroglial cells lining the ependymal canal. This is a major finding, since (i) the ependymal canal epithelium has been demonstrated to harbor neural stem cells (Johansson et al., 1999) and (ii) FGF2 is one of the two necessary mitogens for adult neural stem cells, especially in spinal cord (Weiss et al., 1996). The role of the
FGFRs in the proliferation of neural progenitors in BS and spinal cord is currently unknown. Our findings of high levels of FGFR2 expression in BS and lower levels in the posterior segment of spinal cord support previous suggestions stating that FGF2-induced proliferation of neural progenitor cells in $\mathrm{BS}$ is mediated primarily by FGFR2 while proliferation in spinal cord mainly depends on FGFR1 (Zhang et al., 2003). An alternative is that FGF2 simultaneously activates FGFR1 and 2, perhaps at different points in the regeneration process. Verification of this possibility will require studies of additional time points and might be relevant to the treatment of spinal cord lesions in humans.

\section{CONCLUSION}

The present study shows that, in intact animals, FGFR2 is mainly expressed in the most posterior part of body spinal cord specifically in neurons. However, lesioning the spinal cord at the mid-trunk region produces increased expression of FGFR2 in brainstem neurons and decreased expression in posterior parts of the spinal cord, not only in neurons but also in the neuroglial ependymal cells lining the central canal. This suggests that FGF2 simultaneously activates FGFR1 and 2, perhaps at different points in the regeneration process and thus FGFR2 might play at least an indirect role in the spontaneous regeneration observed in this species and might be relevant to the treatment of spinal cord lesions in humans.

\section{ACKNOWLEDGMENT}

This study was supported by «Région Aquitaine» contract no. $20040301208 \mathrm{~N}$ and N€uromed FP7 project no. 245807. Postdoctoral grants were offered to MM by the AUF (Agence Universitaire de la Francophonie) and the Fondation Singer Polignac.

\section{REFERENCES}

Chevallier, S., M. Landry, F. Nagy and J.M. Cabelguen, 2004. Recovery of bimodal locomotion in the spinal-transected salamander, Pleurodeles waltlii. Eur. J. Neurosci., 20: 1995-2007. DOI: 10.1111/j.1460-9568.2004.03671.x

Cuevas, P., G. Gimenez-Gallego, R. Martinez-Murillo and F. Carceller, 1991. Immunohistochemical localization of basic fibroblast growth factor in ependymal cells of the rat lateral and third ventricles. Acta Anat (Basel), 141: 307-310. DOI: $10.1159 / 000147140$ 
Davis, B.M., J.L. Ayers, L. Koran, J. Carlson and M.C. Anderson et al., 1990. Time course of salamander spinal cord regeneration and recovery of swimming: HRP retrograde pathway tracing and kinematic analysis. Exp. Neurol., 108: 198-213. DOI: 10.1016/0014-4886(90)90124-B

Dionne, C.A., G. Crumley, F. Bellot, J.M. Kaplow and G. Searfoss et al., 1990. Cloning and expression of two distinct high-affinity receptors cross-reacting with acidic and basic fibroblast growth factors. Embo J., 9: 2685-2692. PMID: 1697263

Eckenstein, F.P., K. Kuzis, R. Nishi, W.R. Woodward and C. Meshul et al., 1994. Cellular distribution, subcellular localization and possible functions of basic and acidic fibroblast growth factors. Biochem. Pharmacol., 47: 103-110. DOI: 10.1016/00062952(94)90442-1

Finklestein, S.P., P.J. Apostolides, C.G. Caday, J. Prosser and M.F. Philips et al., 1988. Increased basic Fibroblast Growth Factor (bFGF) immunoreactivity at the site of focal brain wounds. Brain Res., 460: 253-259. DOI: 10.1016/00068993(88)90370-8

Frautschy, S.A., M. Gonzalez, R.M. Murillo, F. Carceller and P. Cuevas et al., 1991. Expression of basic fibroblast growth factor and its receptor in the rat subfornical organ. Neuroendocrinology, 54: 62-67. DOI: $10.1159 / 000125852$

Gomez-Pinilla, F., J.W. Lee and C.W. Cotman, 1992. Basic FGF in adult rat brain: Cellular distribution and response to entorhinal lesion and fimbria-fornix transection. J. Neurosci., 12: 345-355. PMID: 1309575

Gonzalez, A.M., A. Logan, W. Ying, D.A. Lappi and M. Berry et al., 1994. Fibroblast growth factor in the hypothalamic-pituitary axis: Differential expression of fibroblast growth factor-2 and a high affinity receptor. Endocrinology, 134: 2289-2297. DOI: 10.1210/en.134.5.2289

Grothe, C., K. Zachmann and K. Unsicker, 1991. Basic FGF-like immunoreactivity in the developing and adult rat brainstem. J. Comp. Neurol., 305: 328-336. DOI: $10.1002 /$ cne.903050213

Inoue, T., S. Kawaguchi and K. Kurisu, 1998. Spontaneous regeneration of the pyramidal tract after transection in young rats. Neurosci. Let., 247: 151-154. DOI: 10.1016/S0304-3940(98)00297-3
Johansson, C.B., S. Momma, D.L. Clarke, M. Risling and U. Lendahl et al., 1999. Identification of a neural stem cell in the adult mammalian central nervous system. Cell, 96: 25-34. DOI: 10.1016/S0092-8674(00)80956-3

Kang, W., L.C. Wong, S.H. Shi and J.M. Hébert, 2009. The transition from radial glial to intermediate progenitor cell is inhibited by FGF signaling during corticogenesis. J. Neurosci., 29: 14571-14580. DOI: 10.1523/JNEUROSCI.3844-09.2009

Keegan, K., D.E. Johnson, L.T. Williams and M.J. Hayman, 1991. Isolation of an additional member of the fibroblast growth factor receptor family, FGFR3. Proc. Natl. Acad. Sci., USA., 88: 1095-1099. PMID: 1847508

Laemmli, U.K., 1970. Cleavage of structural proteins during the assembly of the head of bacteriophage T4. Nature, 227: 680-685. DOI: 10.1038/227680a0

Landry, M., K. Holmberg, X. Zhang and T. Hokfelt, 2000. Effect of axotomy on expression of NPY, galanin and NPY Y1 and Y2 receptors in dorsal root ganglia and the superior cervical ganglion studied with double-labeling in situ hybridization and immunohistochemistry. Exp. Neurol., 162: 361-384. DOI: $10.1006 /$ exnr.1999.7329

Landry, M., R. Bouali-Benazzouz, S. El Mestikawy, P. Ravassard and F. Nagy, 2004. Expression of vesicular glutamate transporters in rat lumbar spinal cord, with a note on dorsal root ganglia. J. Comparative Neurol., 468: 380-394. DOI: 10.1002/cne. 10988

Matsuda, S., H. Fujita, S. Imaoka, N. Okumura and M. Sakanaka, 1993. Immunoelectron microscopic localization of basic FGF in neuroglias and neurons of the trigeminal mesencephalic and motor nuclei. Okajimas Folia Anat J., 69: 335-343. PMID: 8469523

Matsuda, S., N. Okumura, H. Yoshimura, Y. Koyama and M. Sakanaka, 1992. Basic fibroblast growth factor-like immunoreactivity in Purkinje cells of the rat cerebellum. Neuroscience, 50: 99-106. DOI: 10.1016/0306-4522(92)90384-E

Matsuyama, A., H. Iwata, N. Okumura, S. Yoshida and K. Imaizumi et al., 1992. Localization of basic fibroblast growth factor-like immunoreactivity in the rat brain. Brain Res., 587: 49-65. DOI: 10.1016/0006-8993(92)91427-G

McDonald, J.W. and C. Sadowsky, 2002. Spinal-cord injury. Lancet, 359: 417-425. DOI: 10.1016/S01406736(02)07603-1 
Moftah, M., M. Landry, F. Nagy and J.M. Cabelguen, 2008. Fibroblast growth factor-2 mRNA expression in the brainstem and spinal cord of normal and chronic spinally transected urodeles. J. Neurosci. Res., 86: 3348-3358. DOI: 10.1002/jnr.21776

Moftah, M.Z., S.A. Downie, N.B. Bronstein, N. Mezentseva and J. Pu et al., 2002. Ectodermal FGFs induce perinodular inhibition of limb chondrogenesis in vitro and in vivo via FGF receptor 2. Dev. Biol., 249: 270-282. DOI: 10.1006/dbio.2002.0766

Nordlander, R.H. and M. Singer, 1978. The role of ependyma in regeneration of the spinal cord in the urodele amphibian tail. J. Comp. Neurol., 180: 349374. DOI: 10.1002/cne.901800211

Pettmann, B., G. Labourdette, M. Weibel and M. Sensenbrenner, 1986. The brain Fibroblast Growth Factor (FGF) is localized in neurons. Neurosci. Lett., 68: 175-180. DOI: 10.1016/0304-3940(86)90137-0

Piatt, J., 1955. Regeneration of the spinal cord in the salamander. J. Exp. Zool., 29: 177-207. DOI: 10.1002/jez.1401290109

Qi, M.L., Y. Wakabayashi, H. Haro and K. Shinomiya, 2003. Changes in FGF-2 expression in the distal spinal cord stump after complete cord transection: A comparison between infant and adult rats. Spine, 28: 1934-1940.

DOI: 10.1097/01.BRS.0000083323.38962.2A

Saarimaki-Vire, J., P. Peltopuro, L. Lahti, T. Naserke and A.A. Blak et al., 2007. Fibroblast growth factor receptors cooperate to regulate neural progenitor properties in the developing midbrain and hindbrain. J. Neurosci., 27: 8581-8592. DOI: 10.1523/JNEUROSCI.0192-07.2007

Stevens, H.E., K.M. Smith, M.E. Maragnoli, D. Fagel and E. Borok et al., 2010. Fgfr2 is required for the development of the medial prefrontal cortex and its connections with limbic circuits. J. Neurosci. Official J. Soc. Neurosci., 30: 5590-5602. DOI: 10.1523/JNEUROSCI.5837-09.2010

Stock, A., K. Kuzis, W.R. Woodward, R. Nishi and F.P. Eckenstein, 1992. Localization of acidic fibroblast growth factor in specific subcortical neuronal populations. J. Neurosci., 12: 4688-4700. PMID: 1281493

Tooyama, I., D. Walker, T. Yamada, K. Hanai and H. Kimura et al., 1992. High molecular weight basic fibroblast growth factor-like protein is localized to a subpopulation of mesencephalic dopaminergic neurons in the rat brain. Brain Res., 593: 274-280. DOI: $10.1016 / 0006-8993(92) 91318-9$
Tooyama, I., H.P. Kremer, M.R. Hayden, H. Kimura and E.G. McGeer et al., 1993a. Acidic and basic fibroblast growth factor-like immunoreactivity in the striatum and midbrain in Huntington's disease. Brain Res., 610: 1-7. DOI: 10.1016/00068993(93)91209-B

Tooyama, I., T. Kawamata, D. Walker, T. Yamada and K. Hanai et al., 1993b. Loss of basic fibroblast growth factor in substantia nigra neurons in Parkinson's disease. Neurology, 43: 372-376. PMID: 8437705

Trueb, B., 2011. Biology of FGFRL1, the fifth fibroblast growth factor receptor. Cell. Mol. Life Sci., 68: 95164. DOI: 10.1007/s00018-010-0576-3

Wakabayashi, Y., H. Komori, T. Kawa-Uchi, K. Mochida and M. Takahashi et al., 2001. Functional recovery and regeneration of descending tracts in rats after spinal cord transection in infancy. Spine (Phila Pa 1976), 26: 1215-1222. PMID: 11389386

Weiss, S., C. Dunne, J. Hewson, C. Wohl and M. Wheatley et al., 1996. Multipotent CNS stem cells are present in the adult mammalian spinal cord and ventricular neuroaxis. J. Neurosci., 16: 7599-7609.

Woodward, W.R., R. Nishi, C.K. Meshul, T.E. Williams and M. Coulombe et al., 1992. Nuclear and cytoplasmic localization of basic fibroblast growth factor in astrocytes and CA2 hippocampal neurons. J. Neurosci., 12: 142-152. PMID: 1729432

Yamamoto, T., E. Kardami and J.I. Nagy, 1991. Basic fibroblast growth factor in rat brain: localization to glial gap junctions correlates with connexin43 distribution. Brain Res., 554: 336-343. DOI: 10.1016/0006-8993(91)90213-F

Yamanaka, H., K. Obata, K. Kobayashi, Y. Dai and T. Fukuoka et al., 2007. Activation of fibroblast growth factor receptor by axotomy, through downstream p38 in dorsal root ganglion, contributes to neuropathic pain. Neuroscience, 150: 202-211. DOI: 10.1016/j.neuroscience.2007.08.024

Zhang, F., J.D.W. Clarke and P. Ferretti, 2000. FGF-2 Up-regulation and proliferation of neural progenitors in the regenerating amphibian spinal cord in vivo. Dev. Biol., 225: 381-391. DOI: 10.1006/dbio.2000.9843

Zhang, F., P. Ferretti and J.D.W. Clarke, 2003. Recruitment of postmitotic neurons into the regenerating spinal cord of urodeles. Dev. Dyn., 226: 341-348. DOI: $10.1002 /$ dvdy. 10230 